\title{
Synthesis of trisiloxane-containing alicyclic tetracarboxylic dianhydrides and the characterization of polyimides
}

\begin{abstract}
Tohru Kikuchi
The titular alicyclic tetracarboxylic dianhydrides were synthesized with endo- and/or exo-5-norbornene-2,3-dicarboxylic anhydride and 1,1,3,3,5,5-hexamethyltrisiloxane. The endo-structure tetracarboxylic dianhydride was reported to be a crystal, and could be divided into meso and racemic isomers. By contrast, the exo-structure tetracarboxylic dianhydride was a highly viscous liquid. Polyimides synthesized from these tetracarboxylic dianhydrides and 4,4'-oxydianiline were colorless and organosoluble. The exo-structure polyimide had better mechanical properties and higher glass transition temperatures than the endo-structure polyimides. The elongation at the break of the exo-structure polyimide increased with weight-average molecular weight $(\mathrm{Mw})$ and saturated at $22 \%$ when $\mathrm{Mw}$ was greater than $\mathbf{8 8 0 0 0}$. Polyimides synthesized from the meso and racemic isomers of the endo-structure showed the same thermal properties.
\end{abstract}

Polymer Journal (2012) 44, 1222-1229; doi:10.1038/pj.2012.94; published online 23 May 2012

Keywords: hydrosilylation; norbornene; polyimide; siloxane; stereoisomer; tetracarboxylic dianhydride

\section{INTRODUCTION}

Aromatic polyimides have been used extensively in microelectronics, semiconductors and many other fields, because of their outstanding thermal, electrical and mechanical properties. Recently, however, semi-aromatic or wholly alicyclic polyimides have gained the increasing attention in the optoelectronics field, which requires the colorless and highly transparent polyimides in the near-ultraviolet region.

To derive the above-mentioned polyimides, many alicyclic tetracarboxylic dianhydrides have been synthesized with hydroesterification of unsaturated alicyclic compounds, oxidation of fused alicyclic compounds with nitric acid, hydrogenation of aromatic tetracarboxylic compounds and other methods. However, these methods have the problem of low yield and the necessity of esterification, hydrolysis and dehydration with acetic anhydride before and after the reacting process.

On the other hand, hydrosilylation ${ }^{1-5}$ of endo-5-norbornene dicarboxylic anhydride (endo-NBA) can synthesize the siloxanecontaining tetracarboxylic dianhydrides with a one-step reaction and a high yield.

As the most relevant tetracarboxylic dianhydride, 5,5'-(1,1,3,3, 5,5-hexamethyltrisiloxane-1,5-diyl)bisbicyclo[2.2.1]heptane-2,3-endo-di carboxylic anhydride (endo-TriSXDA) was synthesized with endoNBA and 1,1,3,3,5,5-hexamethyltrisiloxane (HMTS). There are two reports concerning the endo-TriSXDA. One of them characterized the polyimides derived from several diamines, and reported that the melting point of the endo-TriSXDA was $133.4-133.9^{\circ} \mathrm{C} .{ }^{4}$ However, in the other report, the author showed that the endo-TriSXDA could be divided into two types of crystals with different melting points: $143.5-144.5$ and $119.5-121.5^{\circ} \mathrm{C}$. The former was a fine-needle-like crystal, and was not able to be analyzed by X-ray analysis. The latter was a large single crystal and confirmed to be the racemic isomer. ${ }^{5}$

Before the above reports about the endo-TriSXDA, there was a report of the polyimides derived from the DiSXDA (disiloxanecontaining endo- and/or exo-norbornane tetracarboxylic dianhydride). ${ }^{6}$ The repeating structural unit of these pentamethyldisiloxane end-capped polyimides, which were synthesized with the disiloxane equilibration reaction, was the same as that of the polyimides derived from DiSXDA and m-phenylenediamine. Here, only glass transition temperature $(\mathrm{Tg})$ by differential scanning calorimetry was reported about the properties of these polyimides. In addition, the molecular weight of the polyimide derived from endo-DiSXDA and $\mathrm{m}$-phenylenediamine was low, and even the $\mathrm{Tg}$ was not reported.

Thus, it is worthwhile to distinguish endo- from exo-structures when synthesizing trisiloxane-containing tetracarboxylic dianhydrides, as shown in Scheme 1. It is also important to clarify the relationship between the structure and properties of polyimides derived from these tetracarboxylic dianhydrides.

\section{EXPERIMENTAL PROCEDURES}

Materials

For hydrosilylation to synthesize alicyclic tetracarboxylic dianhydrides, endoNBA (mp 166.5-167. ${ }^{\circ} \mathrm{C}$ ), HMTS (Shin-Etsu Chem., Tokyo, Japan; LS-8130), Platinum Complex (Sigma-Aldrich, St Louis, MO, USA; Platinum $(0)-1,3-$ 


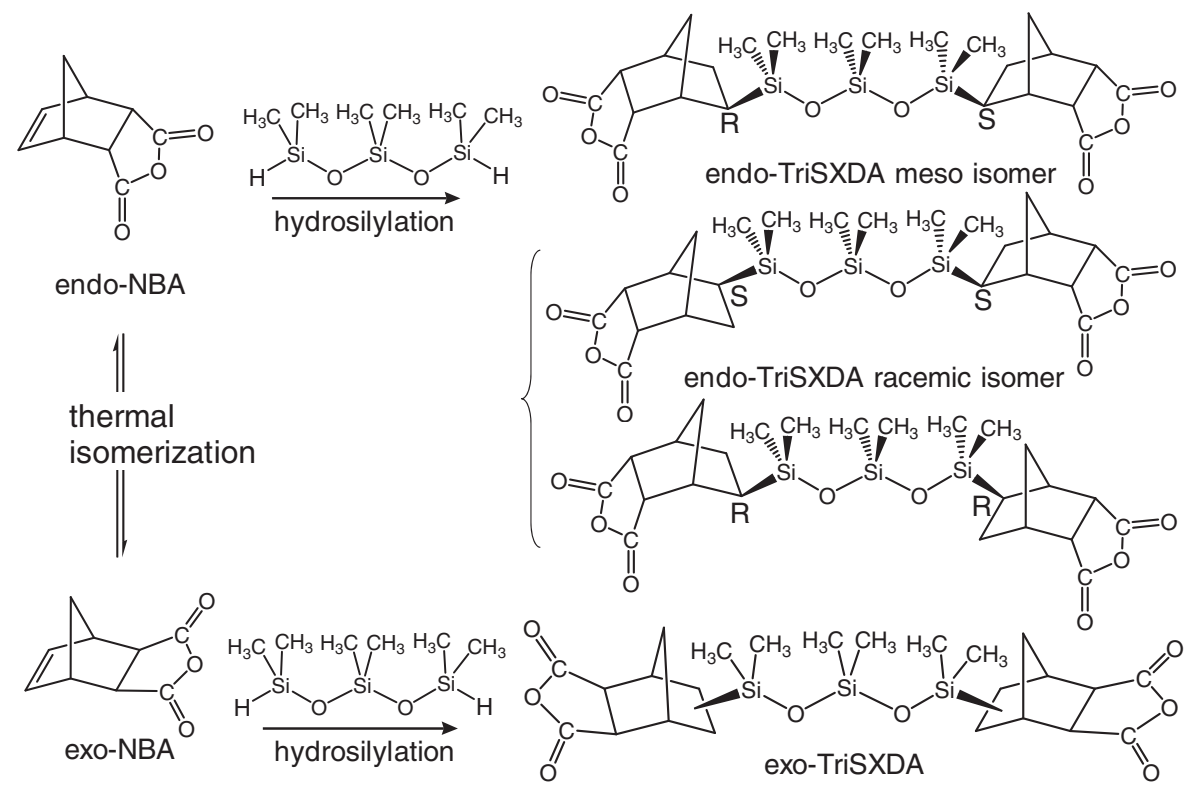

Scheme 1 Synthesis of TriSXDAs.

divinyl-1,1,3,3-tetramethyldisiloxane complex, solution in xylene, 2\% Pt) as the catalyst and toluene as the solvent were commercially available and used without being refined. For the synthesis of polyimides, 4,4'-oxydianiline (ODA), 2-hydroxypyridine as the catalyst and 1,2-dichrolobenzene as the solvent were also commercially available and used as commercially formulated. In addition, acetone and methanol were used for precipitating the polyimides, 1-methyl-2pyrrolidinone was used as the solvent for preparing poly(amic acid), and $\mathrm{N}, \mathrm{N}-$ dimethylacetamide was used as the solvent for preparing polyimide films; these were also commercially available and used as commercially formulated. The exo-NBA (mp 148.0-149.5 ${ }^{\circ} \mathrm{C}$ ), which was available through the thermal isomerization of endo-NBA, was synthesized as described in the literature. ${ }^{7}$

\section{Measurements}

The melting points of the dicarboxylic anhydrides and tetracarboxylic dianhydrides were measured using a capillary-type apparatus at a heating rate of $2{ }^{\circ} \mathrm{C} \mathrm{min}-1$. The viscosity of exo-TriSXDA was measured using a rotational cone-plate-type EH-viscometer by Tokyo Keiki Inc., Tokyo, Japan. The components of hydrosilylation mixture and the purity of tetracarboxylic dianhydrides were determined by gel permeation chromatography (GPC) equipped with polystyrene gel columns (Hitachi Chem., Hitachi-shi, Japan; Gelpack GL-A110, two $500 \mathrm{~mm}$ columns in series, with a Mw exclusion limit of ca. 1500), and a Hitachi L-300 RI detector was used with tetrahydrofuran as an eluent at a flow rate of $1.0 \mathrm{ml} \mathrm{min}^{-1}$. Infrared (IR) spectra were obtained with a Varian 3100FT-IR spectrometer (Varian, Palo Alto, CA, USA) by attenuated total reflection (ATR) method. Elemental analyses were performed with an Elementar vario MICRO cube (Elementar, Hanau, Germany). The nuclear magnetic resonance (NMR) spectra were recorded using tetramethylsilane as an internal standard in $\mathrm{CDCl}_{3}$ on a Bruker BioSpin AV400M (Bruker BioSpin, Rheinstetten, Germany; ${ }^{1} \mathrm{H}$ NMR: $400 \mathrm{MHz}$ ). The number- and weight-average molecular weights $(\mathrm{Mn}$ and $\mathrm{Mw}$ ) of the polyimides were determined by GPC equipped with polystyrene gel columns (Hitachi Chem.; Gelpack GL-R440, GLR450 and GL-400M in series) and a Hitachi L-300 RI detector, and using tetrahydrofuran at a flow rate of $2.0 \mathrm{ml} \mathrm{min}^{-1}$. The system was calibrated using polystyrene standards at room temperature. A thermomechanical analysis was carried out with a Seiko TMA/SS-6200 (Seiko, Chiba-shi, Japan) in tensile mode at a heating rate of $10^{\circ} \mathrm{Cmin}^{-1}$. Differential scanning calorimetry was performed with a Seiko DSC-6200 at a heating rate of $10^{\circ} \mathrm{C} \mathrm{min}-1$ in air. A thermogravimetric analysis was made with a Seiko TG/DTA-6200 at a heating rate of $10^{\circ} \mathrm{C} \mathrm{min}^{-1}$ in air. Ultraviolet-vis spectra of the polyimide films were recorded on a Hitachi U-3310 spectrometer. Mechanical properties were measured with a Shimadzu AGS-5kNG (Shimadzu, Kyoto, Japan) with a $5 \mathrm{mmmin}^{-1}$ drawing speed. Measurements were performed at ambient conditions for film specimens ( $10 \mathrm{~mm}$ wide, $20 \mathrm{~mm}$ long and $20-30 \mu \mathrm{m}$ thick), and the results of at least five samples were averaged.

\section{Synthesis of tetracarboxylic dianhydrides}

Synthesis of meso and racemic isomers of endo-TriSXDA were reported in the previous paper. ${ }^{5}$ The synthesis of exo-TriSXDA is described as follows: exo-NBA $(65.66 \mathrm{~g}, 400 \mathrm{mmol})$ and toluene $(260 \mathrm{~g})$ were placed in a 11 , four-necked, roundbottomed flask, equipped with a magnetic stirrer, a $50 \mathrm{ml}$ dropping funnel, a nitrogen inlet and a thermometer. When the temperature of the reaction mixture reached to $55^{\circ} \mathrm{C}, 1.566 \mathrm{~g}$ of the Pt catalyst solution (Pt: $0.161 \mathrm{mmol}$ ) was added to the flask, and HMTS $(41.69 \mathrm{~g}, 200 \mathrm{mmol})$ was dripped for $2 \mathrm{~h}$ into the flask. The reaction mixture was maintained at $55^{\circ} \mathrm{C}$ for $1 \mathrm{~h}$. A GPC analysis confirmed that the reaction had been completed, leaving no exo-NBA, HMTS or their intermediates (because HMTS reacted with one molecule of exo-NBA) in the mixture. After cooling to the room temperature, activated carbon was added to the mixture to decolorize and remove the catalyst. The colorless filtrate had no crystal precipitation. After drying, a highly viscous liquid $(99.2 \mathrm{~g}, 185 \mathrm{mmol}$, yield: $92.5 \%$ ) with the viscosity of $38.4 \mathrm{~Pa} \cdot \mathrm{s}$ at $40^{\circ} \mathrm{C}$ was obtained. The purity was $99.5 \%$ by GPC analysis.

Results of elemental analysis on $\mathrm{C}_{24} \mathrm{H}_{36} \mathrm{O}_{8} \mathrm{Si}_{3}$ (formula weight: 536.79) were as follows: the calculated values of $\mathrm{C}$ and $\mathrm{H}$ were $53.70 \%$ and $6.76 \%$, respectively, and those of measured values were $53.33 \%$ and $6.75 \%$, respectively. The $v$-values (ATR, $\mathrm{cm}^{-1}$ ) of the IR spectra of tetracarboxylic dianhydrides were as follows: endo-TriSXDA meso isomer; 1848 and 1772 $(\mathrm{C}=\mathrm{O}), 1258\left(\mathrm{Si}-\mathrm{CH}_{3}\right), 1080$ and 1063 (Si-O-Si), and 900 (C-O-C), endoTriSXDA racemic isomer; 1857 and $1777(\mathrm{C}=\mathrm{O}), 1255\left(\mathrm{Si}-\mathrm{CH}_{3}\right), 1082$ and 1048 (Si-O-Si), and 903 (C-O-C), exo-TriSXDA; 1864 and $1774(\mathrm{C}=\mathrm{O}), 1257$ $\left(\mathrm{Si}-\mathrm{CH}_{3}\right), 1074$ and 1034 (Si-O-Si), and 901 (C-O-C). Chemical shift values of ${ }^{1} \mathrm{H}$ NMR spectra $\left(400 \mathrm{MHz}, \mathrm{CDCl}_{3}\right)$ were described in Figure 1 and Table 2.

\section{General polymerization procedure and film preparation of polyimides}

The polyimides were synthesized with the one-pot method described in the previous paper. ${ }^{4}$ The following were placed into a $100 \mathrm{ml}$, four-necked, roundbottomed flask, equipped with a mechanical stirrer, a Dean-Stark trap, a nitrogen inlet and a thermometer, along with tetracarboxylic dianhydride $(5.368 \mathrm{~g}, 10.00 \mathrm{mmol}), \quad$ ODA $(2.002 \mathrm{~g}, 10.00 \mathrm{mmol}), 2$-hydroxypyridine $(0.230 \mathrm{~g})$ and 1,2 -dichrolobenzene $(52.20 \mathrm{~g})$. The mixture was heated at $100{ }^{\circ} \mathrm{C}$ 


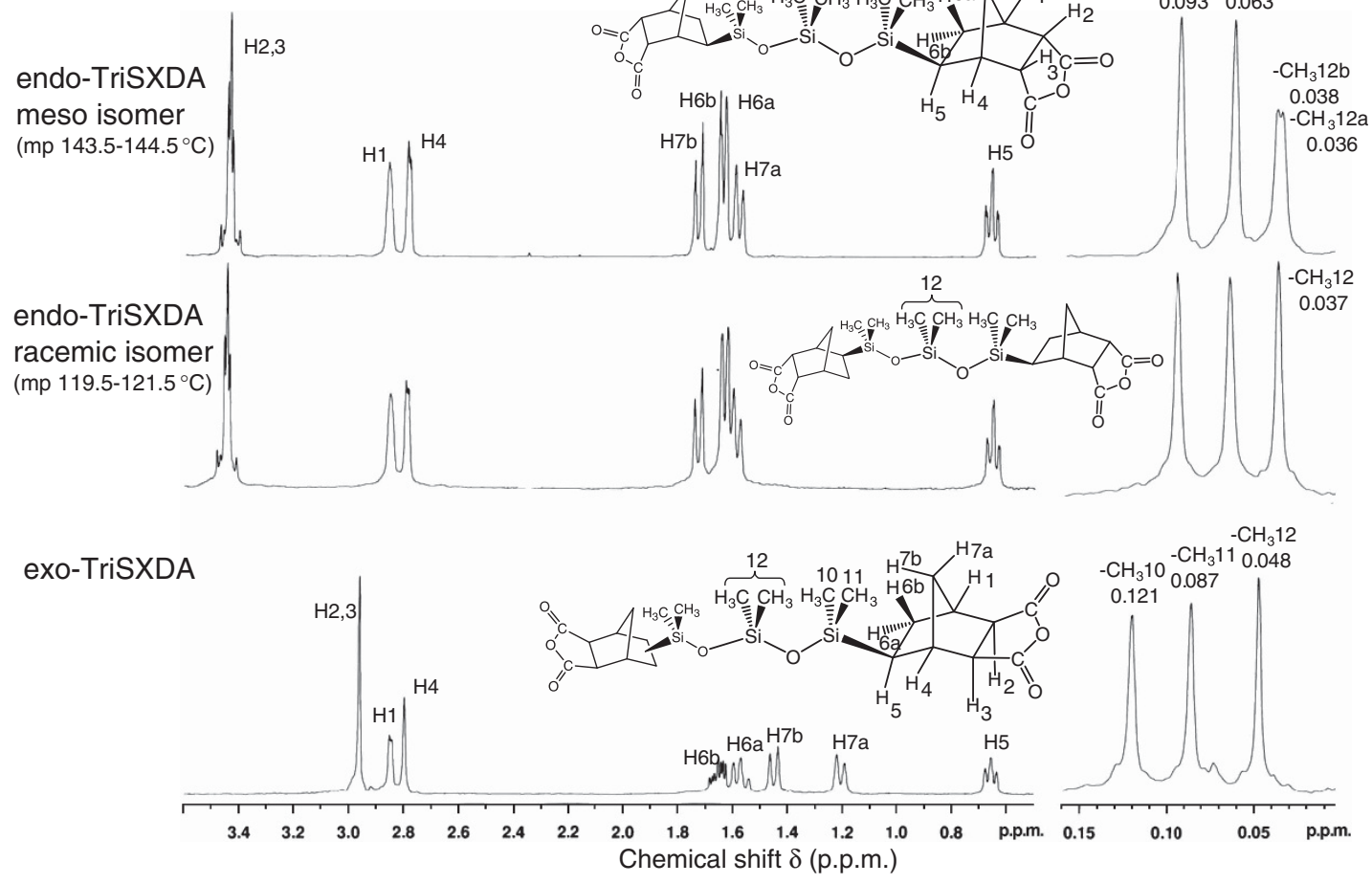

Figure $1^{1} \mathrm{H}$ NMR spectra of the endo- and exo-TriSXDA.

for 30 min until the monomers and the catalyst were fully dissolved. The mixture was then heated to $179^{\circ} \mathrm{C}$ and refluxed at this temperature for $4 \mathrm{~h}$.

After being cooled, the solution was poured while being agitated into $500 \mathrm{~g}$ of methanol to precipitate a polyimide. The polyimide was then dissolved in acetone $(50 \mathrm{~g})$. Methanol was dripped slowly while being agitated into the acetone solution until it separated into two layers. The upper layer was removed by decantation, and methanol was added to the lower layer to precipitate a polyimide. By repeating this procedure, polyimides with the desired molecular weight were prepared.

Next, the prepared polyimide was dissolved in the N,N-dimethylacetamide solution. The concentration was $25 \%$. The polyimide film was prepared by casting the solution onto a glass plate and then heating at $65^{\circ} \mathrm{C}$ for $30 \mathrm{~min}$, and at $165^{\circ} \mathrm{C}$ for $15 \mathrm{~min}$. After cooling, the glass plate was immersed in water and the polyimide film was peeled off in water.

All the polyimides thus synthesized have the same molecular formula, $\left(\mathrm{C}_{36} \mathrm{H}_{44} \mathrm{~N}_{2} \mathrm{O}_{7} \mathrm{Si}_{3}\right)_{\mathrm{x}}$ and the calculated values of $\mathrm{C}, \mathrm{H}$ and $\mathrm{N}$ were $61.68 \%$, $6.33 \%$ and $4.00 \%$, respectively. The results of elemental analyses and molecular weight of the each polyimide were as follows: endo-TriSXDA meso isomer/ODA polyimide: $\mathrm{C}=61.17 \%, \mathrm{H}=6.31 \%$ and $\mathrm{N}=3.86 \% ; \mathrm{Mn}=19800$ and $\mathrm{Mw}=31$ 900. The endo-TriSXDA racemic isomer/ODA polyimide: $\mathrm{C}=61.05 \%$, $\mathrm{H}=6.31 \%$ and $\mathrm{N}=3.92 \% ; \mathrm{Mn}=15700$ and $\mathrm{Mw}=27500$. The exoTriSXDA/ODA polyimide: $\mathrm{C}=61.25 \%, \mathrm{H}=6.26 \%$ and $\mathrm{N}=3.91 \% ; \mathrm{Mn}=76$ $500, \mathrm{Mw}=110000$. The $v$-values $\left(\mathrm{ATR}, \mathrm{cm}^{-1}\right.$ ) of each polyimide was as follows: endo-TriSXDA meso isomer/ODA polyimide: 1773 and $1707(\mathrm{C}=\mathrm{O})$, $1499(\mathrm{Ph}), 1376$ and 1168 (C-N-C), 1237 (br, Ph-O-Ph), 1034 (br, Si-O-Si). The endo-TriSXDA racemic isomer/ODA polyimide: 1778 and $1707(\mathrm{C}=\mathrm{O}), 1499$ (Ph), 1376 and 1168 (C-N-C), 1237 (br, Ph-O-Ph) and 1033 (br, Si-O-Si). The exo-TriSXDA/ODA polyimide: 1775 and $1707(\mathrm{C}=\mathrm{O}), 1500(\mathrm{Ph}), 1378$ and 1177 (C-N-C), 1239 (br, Ph-O-Ph) and 1034 (br, Si-O-Si). Chemical shift values of ${ }^{1} \mathrm{H}$ NMR spectra $\left(400 \mathrm{MHz}, \mathrm{CDCl}_{3}\right)$ were described in Figure 3 and Table 2.

\section{Synthesis of N-phenylimide as model compound}

$\mathrm{N}$-phenylimide was derived from endo-TriSXDA meso isomer $(10 \mathrm{mmol})$ and aniline $(40 \mathrm{mmol})$, with the same method as that used for polyimide synthesis.
After cooling, the reaction solution was poured into a 1:1 (by weight) mixture of water and methanol. The resultant cloudy upper layer of solution was removed, and the excess aniline and 1,2-dichrolobenzene were removed from the lower pale-yellow layer by vacuum distillation to produce a pale yellowishbrown glassy solid of endo-TriSXDA meso $\mathrm{N}$-phenylimide. The yield was $79.6 \%$. The calculated elementary compositions of $\mathrm{C}, \mathrm{H}$ and $\mathrm{N}$ of $\mathrm{C}_{36} \mathrm{H}_{46} \mathrm{~N}_{2} \mathrm{O}_{6} \mathrm{Si}_{3}$ were $62.94 \%, 6.75 \%$ and $4.08 \%$,respectively, and the corresponding measured values were $62.13 \%, 6.69 \%$ and $3.92 \%$, respectively. The $v$ values (ATR, $\mathrm{cm}^{-1}$ ) of IR spectrum were as follows: 1773 and $1706(\mathrm{C}=\mathrm{O})$, $1497(\mathrm{Ph}), 1371$ and $1174(\mathrm{C}-\mathrm{N}-\mathrm{C}), 1256\left(\mathrm{Si}_{-} \mathrm{CH}_{3}\right)$ and 1032 (br, Si-O-Si). Chemical shift values of ${ }^{1} \mathrm{H}$ NMR spectrum $\left(400 \mathrm{MHz}, \mathrm{CDCl}_{3}\right)$ were described in Figure 4 and Table 2.

In the same manner, a pale yellowish-brown glassy solid of exo-TriSXDA $\mathrm{N}$-phenylimide was produced. The yield was $92.6 \%$. Results of analyses for C, $\mathrm{H}$ and $\mathrm{N}$ of this compound were $62.30 \%, 6.69 \%$ and $3.97 \%$, respectively. The $v$-values (ATR, $\mathrm{cm}^{-1}$ ) of IR spectrum were as follows: 1773 and $1702(\mathrm{C}=\mathrm{O})$, $1499(\mathrm{Ph}), 1378$ and $1183(\mathrm{C}-\mathrm{N}-\mathrm{C}), 1256\left(\mathrm{Si}-\mathrm{CH}_{3}\right)$ and 1035 (br, Si-O-Si). Chemical shift values of ${ }^{1} \mathrm{H}$ NMR spectrum $\left(400 \mathrm{MHz}, \mathrm{CDCl}_{3}\right)$ were described in Figure 4 and Table 2.

\section{Synthesis of poly(amic acid) as model compound}

The synthesis of exo-TriSXDA/ODA poly(amic acid) is described as follows: exo-TriSXDA $(6.321 \mathrm{~g}, 11.78 \mathrm{mmol}), \quad$ ODA $(2.358 \mathrm{~g}, 11.77 \mathrm{mmol})$ and 1-methyl-2-pyrrolidinone (49.2 g) were placed in a $100 \mathrm{ml}$, four-necked, round-bottomed flask. The reaction mixture was maintained at $30{ }^{\circ} \mathrm{C}$ for $4 \mathrm{~h}$. The solution was poured into water of $300 \mathrm{ml}$ to precipitate a poly (amic acid). A lump of poly(amic acid) was dissolved in acetone (40 g), and then, acetone solution was dripped slowly into water while being agitated. Powdered poly (amic acid) was dried at room temperature for $5 \mathrm{~h}$ by vacuum $(80 \mathrm{~Pa})$. The yield was $61.6 \%$. The calculated elementary compositions of $\mathrm{C}, \mathrm{H}$ and $\mathrm{N}$ of $\left(\mathrm{C}_{36} \mathrm{H}_{48} \mathrm{~N}_{2} \mathrm{O}_{9} \mathrm{Si}_{3}\right)_{\mathrm{x}}$ were $58.67 \%, 6.56 \%$ and $3.80 \%$,respectively, and corresponding measured values were $57.85 \%, 6.49 \%$ and $3.74 \%$, respectively. The $v$ values (ATR, $\mathrm{cm}^{-1}$ ) of IR spectrum were as follows: 3324 (br, O-H), 1703 (br, $\mathrm{C}=\mathrm{O}), 1532(\mathrm{~N}-\mathrm{H}), 1499(\mathrm{Ph}), 1256\left(\mathrm{Si}_{-}-\mathrm{CH}_{3}\right), 1229(\mathrm{Ph}-\mathrm{O}-\mathrm{Ph})$ and $1035(\mathrm{br}$, 
$\mathrm{Ph}$ and $\mathrm{Si}-\mathrm{O}-\mathrm{Si})$. The ${ }^{1} \mathrm{H}$ NMR spectrum $\left(400 \mathrm{MHz}\right.$, acetone- $\left.\mathrm{d}_{6}\right)$ is shown in Figure 3.

\section{RESULTS AND DISCUSSION}

\section{Synthesis and NMR studies of monomers}

The hydrosilylation of endo- and exo-NBA proceeded stoichiometrically without any byproducts, as confirmed by GPC analyses. Comparing the reactivity of endo- and exo-NBA, it was found that the exo-NBA reaction was completed in a shorter period ( $9 \mathrm{~h}$ vs $3 \mathrm{~h}$ ), despite the latter having half the amount of catalyst (822 p.p.m. vs 402 p.p.m.: molar ratio $[\mathrm{Pt}] /[\mathrm{NBA}])$ and a lower reaction temperature $\left(90^{\circ} \mathrm{C}\right.$ vs $\left.55^{\circ} \mathrm{C}\right)$. The remarkably higher reactivity of exo-NBA comparing with endo-NBA agreed with the report on the hydrosilylation of endo- and exo-NBA with dimethylchlorosilane under the same conditions, in which the time to complete the reaction for exoNBA is $30 \mathrm{~min}$ or less, in contrast to $48 \mathrm{~h}$ for endo-NBA. ${ }^{8}$ According to the another paper, the lower activity of the endo-NBA was due to the charge in the lowest unoccupied molecular orbital (LUMO) and its weak $\pi$-acceptor interaction with the platinum atom. ${ }^{9}$

As described in the introduction, the endo-TriSXDA was divided into two types of crystals. The crystal of lower melting point was

Table 1 Results of polymerization and precipitation

\begin{tabular}{|c|c|c|c|c|c|c|c|}
\hline $\begin{array}{l}\text { Tetracarboxylic } \\
\text { dianhydride }\end{array}$ & $\begin{array}{l}\text { Purity } \\
\text { (\%) }\end{array}$ & $\begin{array}{c}\text { Concentration } \\
\text { (\%) }\end{array}$ & $\begin{array}{c}\text { Precipitation } \\
\text { number }\end{array}$ & $\begin{array}{l}\text { Yield } \\
\text { (\%) }\end{array}$ & $M n$ & $M w$ & $\begin{array}{l}M w / \\
M n\end{array}$ \\
\hline & & & 1 & - & 6800 & 16800 & 2.49 \\
\hline & & 12.5 & 2 & 68 & 11900 & 25600 & 2.15 \\
\hline \multirow[t]{4}{*}{ Endo-meso } & 99.6 & & 4 & 36 & 19800 & 31900 & 1.61 \\
\hline & & & 1 & 95 & 10900 & 45600 & 4.18 \\
\hline & & 15.0 & 3 & 54 & 28400 & 47000 & 1.65 \\
\hline & & & 5 & 40 & 43000 & 65500 & 1.52 \\
\hline \multirow[t]{5}{*}{ Endo-racemic } & 98.4 & 12.5 & 3 & 50 & 15700 & 27500 & 1.75 \\
\hline & & & 6 & 18 & 38900 & 63000 & 1.62 \\
\hline & & & 1 & - & 17300 & 53300 & 3.08 \\
\hline & & 12.5 & 2 & 75 & 25800 & 57700 & 2.24 \\
\hline & & & 3 & 47 & 35300 & 63800 & 1.81 \\
\hline \multirow[t]{5}{*}{ Exo- } & 99.5 & & 4 & 30 & 44800 & 72900 & 1.63 \\
\hline & & & 2 & 79 & 30400 & 56200 & 1.85 \\
\hline & & 15.0 & 3 & 48 & 55900 & 88200 & 1.58 \\
\hline & & & 6 & 18 & 76500 & 110000 & 1.44 \\
\hline & & & 8 & 13 & 88700 & 117000 & 1.32 \\
\hline
\end{tabular}
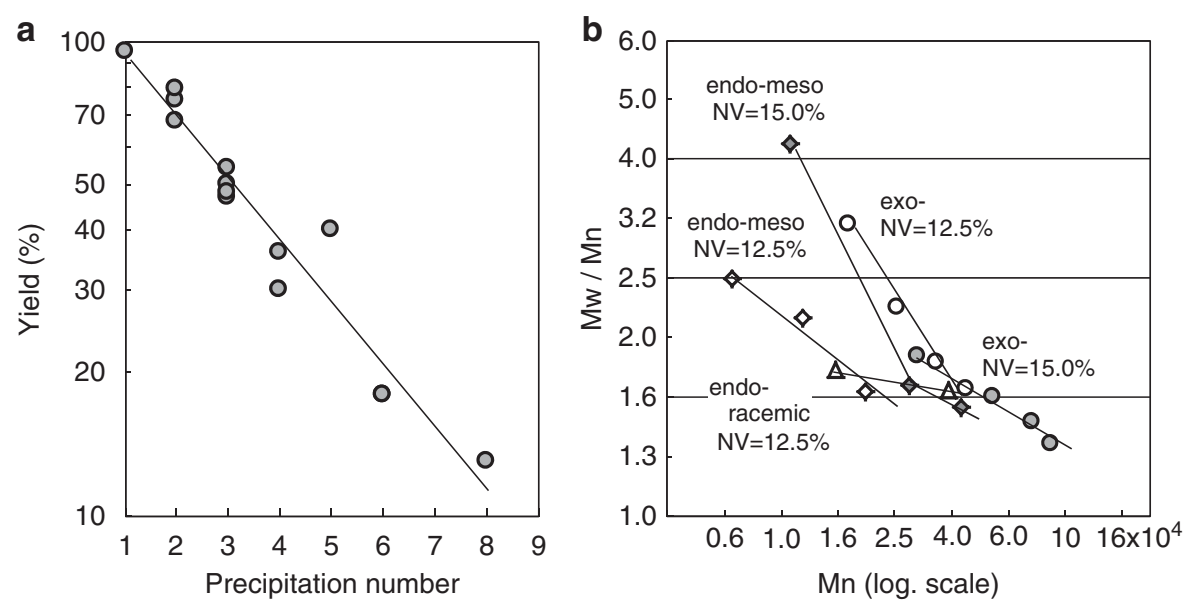

confirmed to be the racemic isomer by X-ray analysis, and that of higher melting point was thought to be a meso isomer according to the reaction mechanism. On the contrary, exo-TriSXDA, which was an extremely highly viscous liquid at room temperature, showed no sign of crystallization even after 3 years standing. From the amount of yield, this is presumed to be a mixture of meso and racemic isomers.

Figure 1 shows the ${ }^{1} \mathrm{H}$ NMR spectra of the tetracarboxylic dianhydrides. The width of the range $0.00-0.15$ p.p.m. is scaled up. The attribution of the protons in the figure is based on the results of the Oak Ridge thermal ellipsoid plot program (ORTEP) of X-ray analysis ${ }^{5}$ and analyzing the two-dimensional spectra of incredible natural abundance double quantum transfer experiment (INADEQUATE), heteronuclear single quantum coherence and nuclear overhauser enhancement spectroscopy. The spectra of meso and racemic isomer of endo-TriSXDA were found to be almost the same, and the only difference lies with the methyl group protons of the center silicon in the highest field. The figures attached to these methyl groups represent their chemical shift values. The two methyl groups of the meso isomer are nonequivalent; therefore, these protons were observed as two separate peaks. On the other hand, those of the racemic isomer are equivalent. Therefore, these protons were observed as a single peak.

And then, other results of analyses for the NMR spectra were as follows. The H6a proton (i.e., methylene proton upfield) is in the exoposition of the norbornane ring for endo-TriSXDA, whereas it is in the endo-position for exo-TriSXDA. The two methyl group protons (i.e., $-\mathrm{CH}_{3} 10$ and $-\mathrm{CH}_{3} 11$ ) bonded with the side silicon exist near the chiral center (i.e, no. 5 carbon). Therefore, these protons show different chemical shift values. From the relationship between these protons and the norbornane ring protons for the NOESY spectra, it is inferred that the silicon atom does not rotate freely.

\section{Preparation of polyimides}

The results of polymerization and precipitation are summarized in Table 1. As the repetitions of precipitation using acetone and methanol increased, the yield of polyimides decreased. The relationship between the yield of all polyimides as logarithmic value and the number of precipitations are shown in Figure 2a. A good linear relationship can be seen (correlation coefficient $r=0.970$ ). Figure $2 \mathrm{~b}$ shows the relationship between $\mathrm{Mn}$ and polydispersity $(\mathrm{Mw} / \mathrm{Mn})$ of polyimides. As the figure indicates, $\mathrm{Mn}$ increased with repeated precipitation and $\mathrm{Mw} / \mathrm{Mn}$ approached toward 1.0. In addition, higher concentration and exo-structure produced the higher Mn polyimides.

Figure 2 Results of precipitation and Mw of polyimides. 
With regards to the film formation of polyimides, endo-polyimides from both meso and racemic isomers maintained the film form until halfway through the drying process. However, when the drying temperature exceeded the $\mathrm{Tg}$, the endo-polyimides developed numerous fine cracks, preventing the formation of films. This is presumably attributable to a change in conformation resulting from molecular movements at temperatures above the Tg. This phenomenon also corresponds to the twisting or distortion of a repeating unit structure, which is inferable via the NMR analysis as mentioned below and the most stable structures of tetracarboxylic dianhydrides from quantum chemical calculation as mentioned in the last section.

\section{Confirmation of imidization}

In the IR spectra of three polyimides, the broad absorption near $3300 \mathrm{~cm}^{-1}$ based on the $\mathrm{O}-\mathrm{H}$ stretching vibration of carboxyl group was not observed at all.

Figure 3 shows the ${ }^{1} \mathrm{H}$ NMR spectra of the polyimides and exoTriSXDA/ODA poly(amic acid) as contrast. The poly(amic acid) was measured with hexadeuteroacetone as solvent, because it is insoluble in deuterochloroform. The width of the ranges $0.00-0.20$ and 6.67.7 p.p.m. is scaled up.

The spectrum of poly(amic acid) is extremely complex compared with the spectra of polyimides. The reason is because of the existence of isomers, which differ in the position where the amide and the carboxyl group joins the norbornane ring. The methyl group protons have the three times higher intensity than the carboxyl group proton and are easy to be observed. However, there is not the methyl group protons coming from poly(amic acid) in the spectra of polyimides. In addition, the existence of the carboxyl group proton was investigated, but there was not the clear peak in the downfield more than 8 p.p.m.

Thus, it is confirmed that the imidization was completed.

\section{NMR studies of polyimides}

The three spectra of the polyimides in Figure 3 were all different to each other. The methyl group protons of the center silicon in the endo-TriSXDA meso isomer/ODA polyimide (endo-meso polyimide) presented two clearly separate peaks. The difference in chemical shift value between the peaks was 0.011 p.p.m., which was larger than the difference for the endo-TriSXDA meso isomer. The methyl group protons of the center silicon in the endo-TriSXDA racemic isomer/ ODA polyimide (endo-racemic polyimide) showed the same peak as the endo-TriSXDA racemic isomer. For the exo-TriSXDA/ODA polyimide (exo-polyimide), the $\mathrm{H} 2$ and $\mathrm{H} 3$ protons were shifted toward the upfield to overlap with the $\mathrm{H} 4$ proton, but the methyl group proton showed a different chemical shift value from the endopolyimides; this was also the case for the tetracarboxylic dianhydride. From these results, it can be concluded that the polyimides maintained the structure of the tetracarboxylic dianhydrides.

The comparison in detail of the chemical shift values of the protons between the tetracarboxylic dianhydrides and the polyimides reveals that the chemical shift values of protons other than the methyl, $\mathrm{H} 2$ and $\mathrm{H} 3$ protons also changed. The changes in chemical shift values are considered to be a result of the transformation of protons into a polyimide, which causes the change in electronic and magnetic shielding state. To confirm the above-mentioned speculation, $\mathrm{N}$-phenylimides of endo-TriSXDA meso isomer and exo-TriSXDA were synthesized as model compounds. The ${ }^{1} \mathrm{H}$ NMR spectra and

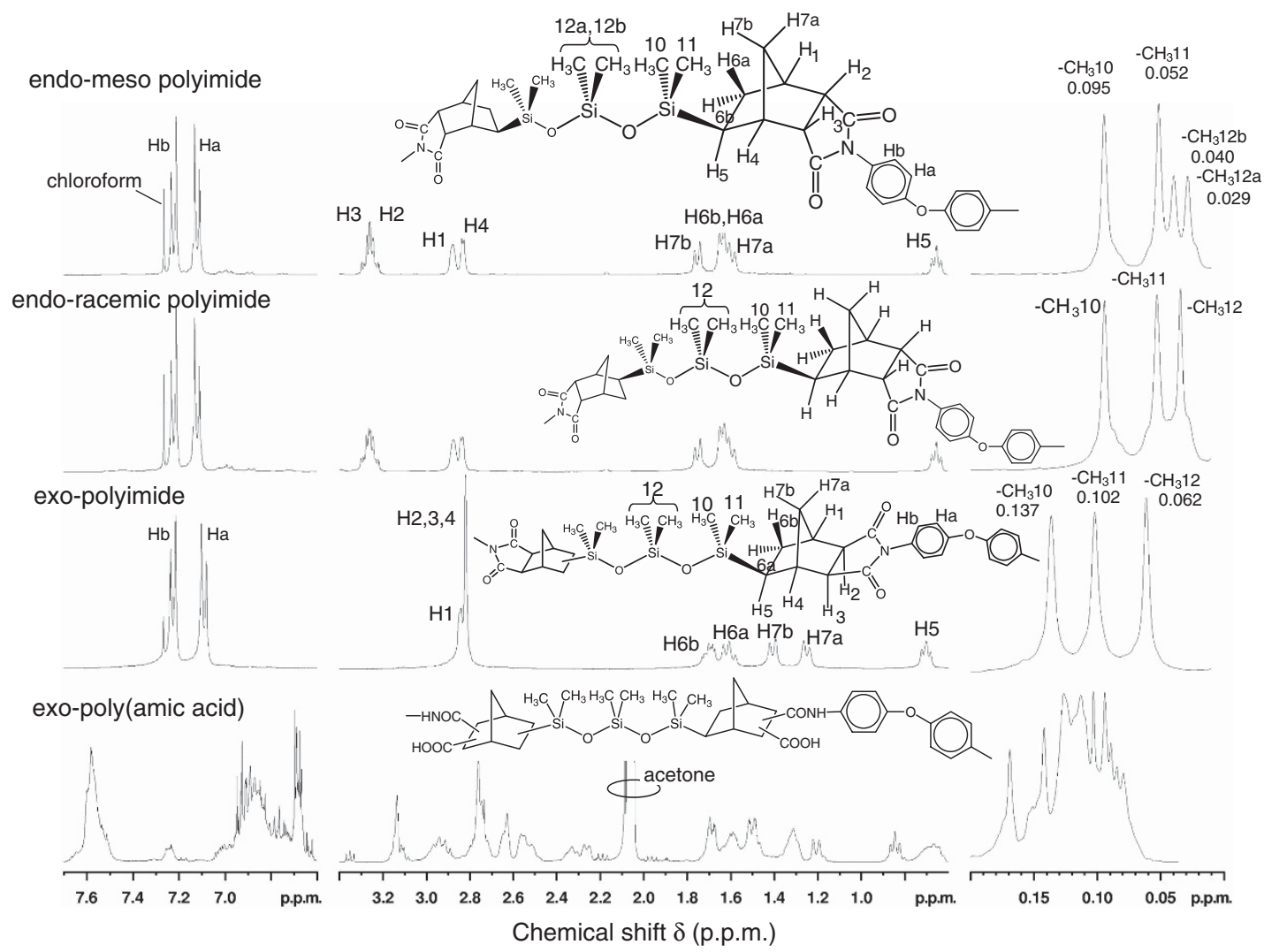

Figure $3{ }^{1} \mathrm{H}$ NMR spectra of the endo-, exo-polyimides and exo-polyamic acid. 
endo-meso phenylimide
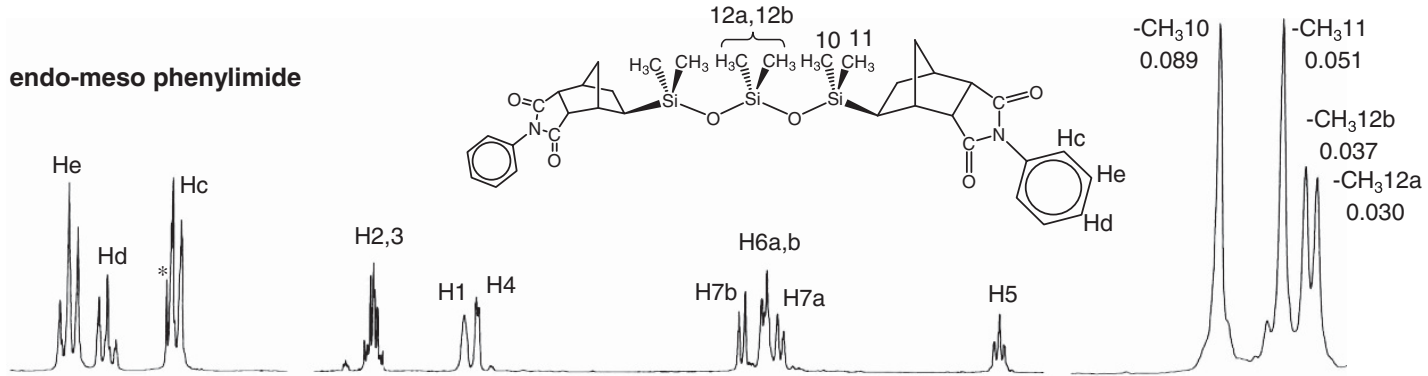

exo- phenylimide
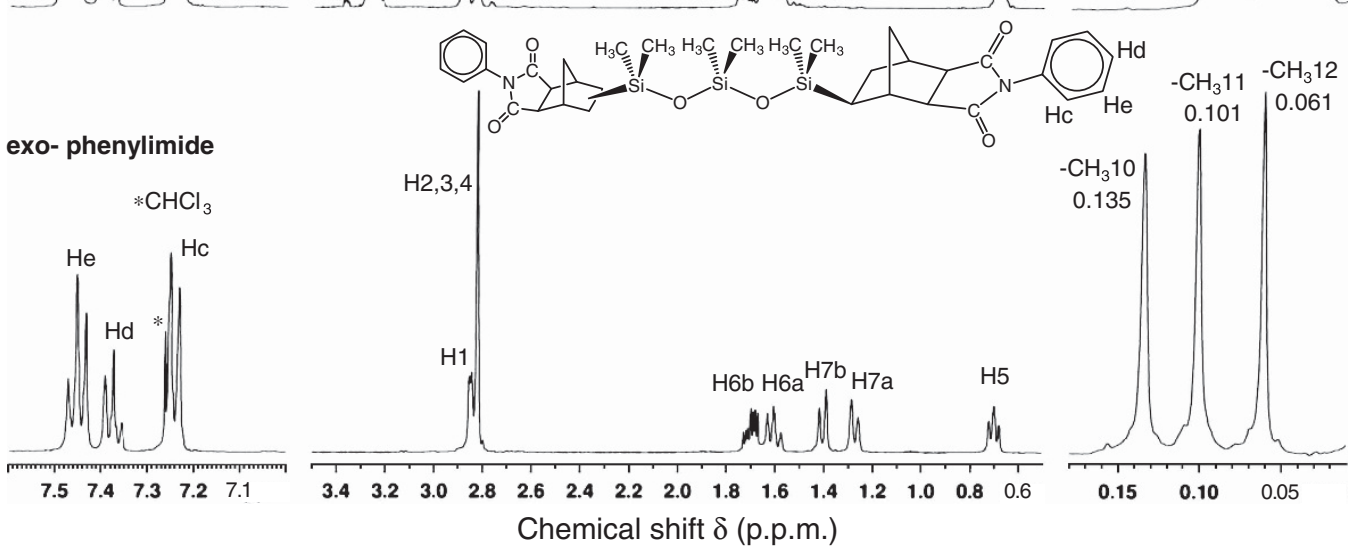

Figure $4{ }^{1} \mathrm{H}$ NMR spectra of endo-meso and exo-phenylimides.

Table 2 Fluctuation of chemical shift values

\begin{tabular}{|c|c|c|c|c|c|c|c|c|c|c|}
\hline \multirow[b]{2}{*}{ Proton } & \multicolumn{5}{|c|}{ Endo-meso } & \multicolumn{5}{|c|}{ exo- } \\
\hline & $\begin{array}{c}\text { Tetracarboxylic } \\
\text { dianhydride }\end{array}$ & $|\Delta|$ & Phenylimide & $I \Delta I$ & Polyimide & $\begin{array}{c}\text { Tetracarboxylic } \\
\text { dianhydride }\end{array}$ & $I \Delta I$ & Phenylimide & $|\Delta|$ & Polyimide \\
\hline $\mathrm{H} 1$ & 2.866 & 0.013 & 2.879 & 0.000 & 2.879 & 2.847 & 0.001 & 2.848 & 0.006 & 2.842 \\
\hline $\mathrm{H} 2,3$ & 3.432 & 0.175 & 3.257 & 0.004 & 3.261 & 2.961 & 0.140 & & & \\
\hline $\mathrm{H} 4$ & 2.790 & 0.036 & 2.826 & 0.007 & 2.833 & 2.798 & 0.023 & 2.821 & 0.001 & 2.820 \\
\hline $\mathrm{H} 6 \mathrm{~b}$ & 1.662 & 0.001 & 1.661 & 0.010 & 1.651 & 1.653 & 0.044 & 1.697 & 0.004 & 1.701 \\
\hline $\mathrm{H} 7 \mathrm{a}$ & 1.580 & 0.005 & 1.585 & 0.009 & 1.594 & 1.207 & 0.067 & 1.274 & 0.022 & 1.252 \\
\hline $\mathrm{H} 7 \mathrm{~b}$ & 1.736 & 0.006 & 1.742 & 0.012 & 1.754 & 1.450 & 0.045 & 1.405 & 0.002 & 1.407 \\
\hline$-\mathrm{CH}_{3} \mathrm{IO}$ & 0.093 & 0.004 & 0.089 & 0.006 & 0.095 & 0.121 & 0.014 & 0.135 & 0.002 & 0.137 \\
\hline$-\mathrm{CH}_{3} \mathrm{Il}$ & 0.063 & 0.012 & 0.051 & 0.001 & 0.052 & 0.087 & 0.014 & 0.101 & 0.001 & 0.102 \\
\hline
\end{tabular}

changes in chemical shift values are shown in Figure 4 and Table 2. Comparing chemical shift values between the N-phenylimide and polyimide of exo-TriSXDA, the value changes occurred only in the $\mathrm{H} 1, \mathrm{H} 6 \mathrm{~b}$ and $\mathrm{H} 7 \mathrm{a}$ protons. For the endo-TriSXDA meso isomer, however, such changes occurred in most of the protons. Therefore, it can be inferred that the changes in the chemical shift value were caused not only by imidization, or a change in the electronic state, but also by polymerization, which presumably generated twisting or distortion in the structure of the repeating unit of a polyimide. It also explains why endo-polyimides did not show the high molecular weight.

\section{Properties of polyimides}

The solubility of the polyimides was tested qualitatively in several solvents and the results are summarized in Table 3. All the polyimides were insoluble in methanol and separated into two separate layers in toluene. However, they dissolved readily in the other solvents.

The Tg by differential scanning calorimetry and the $5 \%$ weight loss temperature (Td5) by thermogravimetric analysis of endo-polyimides are shown in Table 4. There are no differences in the values of thermal properties between the meso and racemic isomers.

The exo-polyimides had good film formability in contrast with endo-polyimides even when Mw was 56200 . Because they are soluble 
in acetone, polyimides of various $\mathrm{Mw}$ were prepared by repeating the fractional precipitation. Table 5 shows the characteristics of the obtained exo-polyimides.

Many of the characteristic values remain almost unchanged by Mw. However, the value of elongation at break under tensile testing increased with $\mathrm{Mw}$, reaching a constant value when $\mathrm{Mw}$ became 88000 or higher.

Despite the change in elongation with $\mathrm{Mw}$, the value of tensile strength did not change, because the elongation reached the yield point at approximately $7 \%$ elongation. In other words, tensile strength is equated with yield strength, and elongation is equated with fracture strain.

As shown in the table, the $\mathrm{Tg}$ of the exo-polyimide was $10-15^{\circ} \mathrm{C}$ higher than that of the endo-polyimides. This result is contrastive to the previously reported case of the endo- and exo-polyimides, which use DiSXDA and m-phenylenediamine for repeating structural unit,

Table 3 Solubility of polyimides

\begin{tabular}{|c|c|c|c|c|c|c|c|}
\hline \multirow[b]{2}{*}{ Unit structure } & \multirow[b]{2}{*}{$M w$} & \multicolumn{6}{|c|}{ Solvents } \\
\hline & & Methanol & Toluene & Acetone & THF & NMP & $D M A C$ \\
\hline \multicolumn{8}{|l|}{ Endo } \\
\hline Meso & 65500 & $-{ }^{a}$ & $+1-a$ & $++^{a}$ & ++ & ++ & ++ \\
\hline Racemic & 63000 & - & $+1-$ & ++ & ++ & ++ & ++ \\
\hline Exo & 56200 & - & $+1-$ & ++ & ++ & ++ & ++ \\
\hline
\end{tabular}

Abbreviations: THF, tetrahydrofuran; NMP, N-methyl-2-pyrrolidinone; DMAc, N,Ndimethylacetamid.

The qualitative solubility was determined by dissolving $0.1 \mathrm{~g}$ of polyimides in $1.0 \mathrm{~g}$ of solvent.

$\mathrm{a}_{+}+$Soluble at room temperature; $+/$- phase separate; - insoluble.

Table 4 Thermal properties of the endo-polyimides

\begin{tabular}{lccc}
\hline Unit structure & $M w$ & $\operatorname{Tg}\left({ }^{\circ} \mathrm{C}\right)^{\mathrm{a}}$ & $\operatorname{Td5}\left({ }^{\circ} \mathrm{C}\right)^{\mathrm{b}}$ \\
\hline Meso & 31900 & 126 & - \\
& 65500 & 129 & 482 \\
Racemic & 27500 & 131 & - \\
& 63000 & 126 & 485
\end{tabular}

Abbreviation: DSC, differential scanning calorimetry.

a Glass transition temperature $(\mathrm{Tg})$ was measured by DSC at heating rate of $10^{\circ} \mathrm{C} \mathrm{min}-1$ in air. bTemperature at which $5 \%$ weight loss was recorded by thermogravimetry at heating rate of $10^{\circ} \mathrm{C} \mathrm{min}^{-1}$ in air.

Table 5 Thermal and mechanical properties of the exo-polyimide

\begin{tabular}{|c|c|c|c|c|c|c|c|}
\hline \multirow[b]{2}{*}{$M w$} & \multicolumn{2}{|c|}{$\operatorname{Tg}\left({ }^{\circ} \mathrm{C}\right)$} & \multirow{2}{*}{$\begin{array}{c}C T E^{D} \\
\left(\times 10^{-6} K^{-1}\right)\end{array}$} & \multirow{2}{*}{$\begin{array}{l}T d 5 \\
(\mathrm{C})\end{array}$} & \multirow{2}{*}{$\begin{array}{l}\text { Strength } \\
\text { (MPa) }\end{array}$} & \multirow{2}{*}{$\begin{array}{l}\text { Modulus } \\
\text { (GPa) }\end{array}$} & \multirow{2}{*}{$\begin{array}{c}\text { Elongation } \\
(\%)\end{array}$} \\
\hline & $D S C$ & $T M A^{\mathrm{a}}$ & & & & & \\
\hline 57700 & 140 & 141 & 91 & 466 & 45 & 1.64 & 6.5 \\
\hline 56200 & - & 140 & 101 & - & 41 & 1.53 & 6.4 \\
\hline 63800 & 141 & 142 & 94 & 465 & 39 & 1.47 & 9.7 \\
\hline 72900 & 142 & 142 & 92 & 456 & 38 & 1.46 & 14 \\
\hline 88200 & - & 138 & 102 & - & 43 & 1.54 & 22 \\
\hline 110000 & 136 & 140 & 89 & 460 & 43 & 1.54 & 21 \\
\hline 117000 & 143 & 143 & 89 & 460 & 50 & 1.42 & 22 \\
\hline
\end{tabular}

Abbreviations: DSC, differential scanning calorimetry; TMA, thermomechanical analyses; CTE, coefficient of thermal expansion.

a Measured by TMA with extension mode applying load of $5 \mathrm{~g}$ at heating rate of $10^{\circ} \mathrm{C} \mathrm{min}^{-1}$ ${ }^{\circ} \mathrm{CTE}$ was determined by TMA range $30-100^{\circ} \mathrm{C}$ where the Tg value of $187^{\circ} \mathrm{C}$ was the same for the endo- and exopolyimides. ${ }^{6}$ The reason of the same Tg for endo- and exo-polyimides of m-phenylenediamine may come from the rigid portion joined to dimethylsiloxane chain. Thus, the $\mathrm{Tg}$ of the polyimides may be mainly determined by the micro-Brownian motion of the flexible dimethylsiloxane chain.

On the other hand, the polyimides studied in this paper are synthesized from ODA, which has an ether linkage as bent bond. Comparing with polyimides synthesized from $\mathrm{m}$-phenylenediamine mentioned above, the sizes of the rigid portion are small. In contrast to strongly bent rigid portion of endo-polyimide, the rigid portion of the exo-polyimide is extended. As a result, the polymer chain of the exo-polyimide easily takes an extended structure. Thus, the exopolyimide may have a denser stacked structure compared with endopolyimides, and the Tg may also become higher due to the effects of the neighboring polymer chain.

The above-mentioned result agrees with the report by Matsumoto et $a l,{ }^{10}$ in which the values of $\mathrm{Tg}$ of polyimide synthesized using either norbornane-2,3-endo; 5,6-exo-tetracarboxylic dianhydride as bent structure and norbornane-2,3-exo; or 5,6-exo-tetracarboxylic dianhydride as extended structure with 1,3-bis(4-aminophenoxy) benzene were evaluated, and the $\mathrm{Tg}$ of the latter $\left(225^{\circ} \mathrm{C}\right)$ was reported to be $14^{\circ} \mathrm{C}$ higher than that of the former $\left(211^{\circ} \mathrm{C}\right)$.

Also, as shown in Table 5 of mechanical properties, the higher $\mathrm{Mw}$ resulted in the higher elongation. The flexible film formability of exopolyimides may come from the high elongation due to the extended polymer structure. The modulus and elongation in Table 5 are three times higher than endo-polyimide, for which the modulus, strength and elongation were reported to be $0.56 \mathrm{GPa}, 52 \mathrm{MPa}$ and $7.9 \%,{ }^{4}$ respectively, though another paper reported that the modulus of endo-polyimide estimated from the strength and elongation is $1.6 \mathrm{GPa},{ }^{11}$ which is almost the same value in Table 5 .

Figure 5 shows the ultraviolet-visible transmission spectra of the polyimides. The films for measurement were prepared by drying on a glass plate at $80^{\circ} \mathrm{C}$ for $30 \mathrm{~min}$. The measurement of the endo-meso polyimide was extremely difficult because the film was fragile. The cutoff wavelength was $290 \mathrm{~nm}$ for both endo-meso and exo-polyimide films, and they became transparent at above $350 \mathrm{~nm}$. However, the exopolyimide showed a higher transparency at around $300 \mathrm{~nm}$.

\section{Molecular structure of tetracarboxylic dianhydrides}

The above-mentioned essentials are as follows: (1) the synthesizing condition of endo-TriSXDA is more intense than exo-TriSXDA; (2)

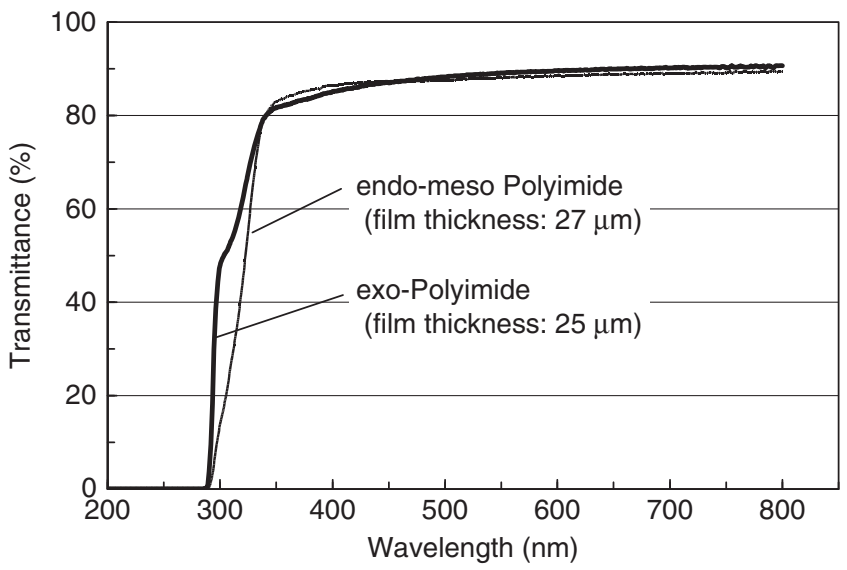

Figure 5 Ultraviolet-vis transmission spectra of polyimides. 


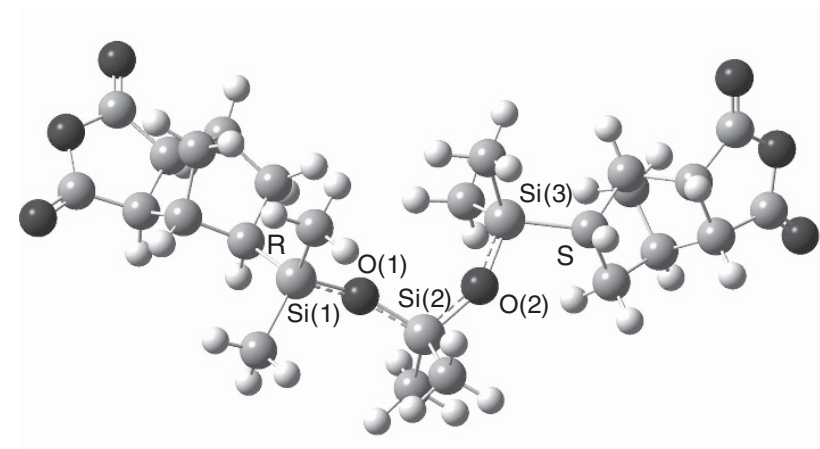

exo-TriSXDA-meso

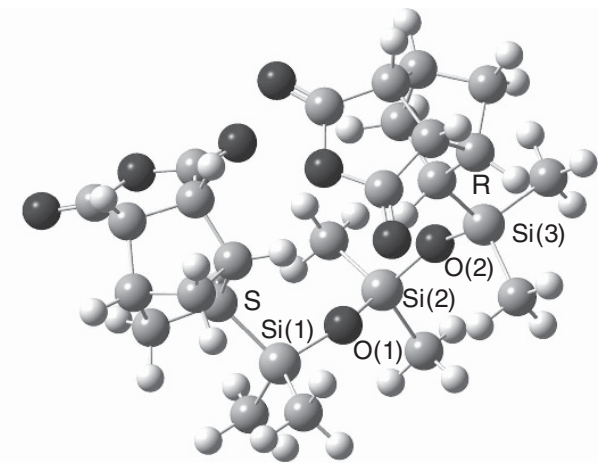

endo-TriSXDA-meso

Figure 6 Optimized structures of tetracarboxylic dianhydrides.

the changes in the chemical shift value of endo-polyimide were caused not only by imidization, but also by polymerization; (3) the molecular weight of endo-polyimides is lower than exo-polyimide; (4) the endopolyimides are inferior to ability to form a film.

It is thought that these results are due to the molecular structure of tetracarboxylic dianhydrides as conveniently illustrated in Scheme 1. To understand the more reasonable structure, the most stable structures were derived from quantum chemical calculation using the Gaussian 09 software implementing the B3LYP functional with the 6-31 G(d) basis set.

Figure 6 shows the each optimized structure of exo- and endoTriSXDA meso isomer. The two anhydride groups of exo-TriSXDA are located at the ends of molecules, and the molecular structure is extended. On the other hand, the anhydride groups of endo-TriSXDA are located closely, and the molecular structure is spherically shrunk. The structure of endo-TriSXDA is obviously different from that shown in the Scheme 1. Thus, the consideration about the molecular structure is useful to understand the properties of the endo- and exopolyimides.

\section{CONCLUSION}

The exo-TriSXDA synthesized through the hydrosilylation of exoNBA and HMTS was a highly viscous liquid, but by contrast, endoTriSXDA from endo-NBA were crystal. Polyimides synthesized from these tetracarboxylic dianhydrides and ODA maintained the original stereo structure. The exo-polyimide had the excellent capability to form film, enabling the measuring of many characteristics. On the other hand, in the case of endo-polyimides, only thermal characteristics were able to be measured because of their poor film-formability. The endo-meso and endo-racemic polyimides showed the same $\mathrm{Tg}$ and Td5. In the case of exo-polyimide, most of those values were constant and irrespective of the Mw value when the Mw exceeded 56000 , except for the elongation at break, which increased with $\mathrm{Mw}$ and reached a steady value when $\mathrm{Mw}$ exceeded 88000 . Comparing the characteristics of the endo- with exo-polyimide, it was found that the $\mathrm{Tg}$ of the latter was higher than the former, and vice versa concerning Td5. It can be concluded that the above results are caused by the difference in endo- and exo-TriSXDA structures.

1 Swint, S. A. \& Buse, M. A. A disiloxane equilibration approach to the preparation and characterization of 5,5'-(1,1,3,3-tetramethyldisiloxane-1,3-diyl)bisbicyclo[2.2.1]heptane-2,3-dicarboxylic anhydride. J. Organomet. Chem. 402, 145-153 (1991).

2 Andre, S., Guida-Pietrasanta, F., Rousseau, A., Boutevin, B. \& Caporiccio, G. Synthesis and thermal properties of telechelic $\alpha, \omega$-bis anhydride oligosiloxanes. Polymer 42, 5505-5513 (2001).

3 Wu, S., Hayakawa, T., Kikuchi, R., Grunzinger, S. J. \& Kakimoto, M. Synthesis and characterization of semiaromatic polyimides containing POSS in main chain derived from double-decker-dhaped silsesquioxane. Macromolecules 40, 5698-5705 (2007).

4 Wu, S., Hayakawa, T. \& Kakimoto, M. Synthesis and characterization of organosoluble polysiloxaneimides derived from siloxane-containing aliphatic dianhydride and various aromatic viamines. High Perform. Polymers 20, 281-295 (2008).

5 Kikuchi, T. Synthesis and crystal structure of trisiloxane-containing alicyclic tetracarboxylic dianhydride. X-ray Struct. Anal. Online 27, 57-58 (2011).

6 Swint, S. A. \& Buse, M.A. Synthesis of poly(imidosiloxanes) via disiloxane equilibration reactions. Macromolecules 23, 4514-4518 (1990).

7 Craig, D. The rearrangement of endo-3,6-Methylene-1,2,3,6-tetrahydro-cis-phthalic anhydride. J. Am. Chem. Soc. 73, 4889-4892 (1951).

8 Eddy, V. J. \& Hallgren, J. E. Effects of proximate polar groups on the rates of hydrosilylation. J. Org. Chem. 52, 1903-1906 (1987).

9 Trofimov, A. E., Skvortsov, A. N., Pashnova, L. V. \& Skvortsov, N. K. Hydrosilation of endo-cis-5-Norbornene-2,3-dicarboxylic anhydride. Russian J. General Chem. 68, 572-577 (1998).

10 Matsumoto, T. \& Kurosaki, T. Soluble and colorless polyimides from bicyclo[2.2.2]octane-2,3,5,6-tetracarboxylic 2,3:5,6-dianhydrides. Macromolecules 30, 993-1000 (1997).

11 Nielsen, L. E. Mechanical Properties of Polymers and Composites (Marcel Dekker, New York, 1974) Japanese translation: Onogi, S p181 (Kagaku-Dojin: Kyoto, 1983). 